\title{
Contextual Influences on the Individual Life Course: Building a Research Framework for Social Epidemiology*
}

\section{Influencias Contextuales en el Ciclo Vital Individual: Construyendo un Marco de Investigación para la Epidemiología Social}

\author{
Juan Merlo \\ Lund University, Sweden
}

\begin{abstract}
Individual health is not only individual responsibility, but also depends on the social contexts that condition the individual across the life course. However, while it is of high public health relevance to identify these contextual influences, they still remain poorly understood, and the research performed so far has suffered from severe limitations. This paper presents a research agenda for social epidemiology that underlines a number of novel concepts, ideas, and unanswered questions deserving future investigation. The paper presents a conceptual framework intended to organize the investigation of geographical, socioeconomic, and cultural disparities in health. This framework identifies five main areas of research: (1) identifying the relevant contexts that influence individual health by measuring general contextual effects, (2) measuring contextual characteristics, the specific effects of these characteristics on individual health and their underlying cross-level mechanisms, (3) investigating general and specific contextual effects from a longitudinal, a life-course perspective and across generations, (4) developing quasi-experimental methods (e.g., family-based designs) for the analysis of causal effects in contextual analyses, and (5) using the achieved scientific knowledge for planning and evaluating interventions. The proposed framework emphasizes that future research in social epidemiology should question the current means-centric reductionism that is mostly concerned with the identification of (contextual) risk factors, and it stresses the need to deliberately investigate determinants of variance. In fact, social epidemiology is not only interested in increasing the (mean) health of the population, but also in understanding and decreasing inappropriate health inequalities (variance).

Keywords: contextual effects, health inequalities, life course, multilevel analyses, public health, social epidemiology.
\end{abstract}

Resumen. La salud individual no depende sólo de la responsabilidad individual, sino también depende de los contextos sociales que condicionan al individuo a lo largo de su ciclo vital. Sin embargo, aunque la identificación de esas influencias contextuales es de una gran relevancia para la salud pública, su comprensión es todavía pobre y la investigación realizada hasta ahora presenta importantes limitaciones. Este trabajo presenta una agenda de investigación para la epidemiología social donde se subrayan un conjunto de nuevos conceptos, ideas y cuestiones pendientes para la investigación futura. El marco conceptual que se presenta trata de organizar la investigación de las desigualdades geográficas, socioeconómicas y culturales en salud. Este marco identifica cinco áreas principales de investigación: (1) identificar los contextos relevantes que influyen en la salud individual a través de la medida de los efectos contextuales generales, (2) medida de las características contextuales, los efectos específicos de esas características en la salud individual y los mecanismos inter-nivel subyacentes, (3) investigar los efectos contextuales generales y específicos longitudinalmente desde una perspectiva del ciclo vital y entre generaciones, (4) desarrollar métodos cuasi-experimentales (por ejemplo, diseños basados en familias) para investigar los efectos contextuales en análisis contextuales, y (4) utilizar el conocimiento científico obtenido para planificar y evaluar intervenciones. El marco conceptual propuesto enfatiza que la investigación futura en epidemiología social debería cuestionar el reduccionismo que suponen los acercamientos centrados en las medias, preocupados fundamentalmente en la identificación de factores (contextuales) de riesgo, y subraya la necesidad de investigar deliberadamente los determinantes de la varianza. La epidemiología social, de hecho, no sólo está interesada en incrementar la salud (la media), sino también en comprender y reducir las desigualdades en salud (la varianza).

Palabras clave: análisis de multinivel, ciclo vital, desigualdades en salud, efectos contextuales, epidemiología social, salud pública.

Correspondence: Juan Merlo. Unit for Social Epidemiology, CRC, Faculty of Medicine, Lund University, SE-20502 Malmö, Sweden. Email: juan.merlo@med.lu.se

* Versión en castellano disponible en [Spanish version available at]: www.psychosocial-intervention.org 
I present a research agenda for social epidemiology that encompasses a number of novel concepts, ideas, and unanswered questions deserving future research activity. I build up a conceptual framework intended to organize the investigation of socioeconomic, geographical or cultural (e.g., conditioned by one's country of birth or gender) disparities in health.

A main idea in this essay is that our life develops longitudinally within a complex system of socio-geographical levels. We are not isolated beings getting older; rather, we are parts of collective bodies (Merlo, Ohlsson, Lynch, Chaix, \& Subramanian, 2009a) that condition our health over and above individual characteristics.

The conceptual framework that I introduce was initially conceived for studies in the field of social epidemiology. However, I believe it is also useful in social psychology, community psychology and psychosocial intervention. The framework is valid for investigating any individual health or behavioural outcome from e.g., myocardial infarction and smoking to intimate partner violence (IPV), or child maltreatment.

\section{Avoiding the psychologistic fallacy and improving the validity of observational analyses}

The validity of the knowledge achieved today in many fields of medicine and psychology is threatened by the perils of the so called psychologistic fallacy. This is an inferential fallacy that appears by neglecting the influence of the context when drawing inferences based on individual level analyses. Giving a classical example, let say that we are interested in knowing why people born in a specific country have a higher risk for IPV. We perform a study and identify that the association with IPV is mediated by substance abuse. As a result of the analysis the local social authorities, aiming to prevent IPV, launch an intervention to confront the problem of substance abuse among those immigrants. However, rather than blaming the immigrants for their unhealthy life-style, we should consider the fact this group of emigrants might be a minority suffering of structural discrimination. This structural discrimination may, in turn, promote both substance abuse, and increase incidence of IPV among emigrants. That is, when biased by the psychologistic fallacy we disregard the context, and assume that individual level outcomes are only explained by individual level characteristics.

In our modern research tradition many determinants of health and health care are investigated at the individual level and even at the genetic and the molecular levels. However, people are both social and biological organisms and there is a growing understanding that individual health and health related behaviour are not only individual responsibilities but they also depends on the social context that conditions the individual across the life course (Ben-Shlomo \& Kuh, 2002; Kaplan, 1999; Macintyre, Ellaway, \& Cummins, 2002).

\section{The causal validity of contextual observational analyses is being questioned}

Today, social inequalities in health are being extensively documented among adult populations, and at the individual level the mechanisms behind these inequalities have been widely investigated (Davey Smith, BenShlomo, \& Lynch, 2002; Davey Smith \& Lynch, 2003; Lynch \& Kaplan, 2000). Also, a growing number of empirical studies suggest that contextual factors may engender important effects on health (Chaix, 2009; Diez Roux \& Mair, 2010). From a multilevel perspective it is assumed that individual health is affected not only by individual characteristics but also by the collective context in which individuals interact. In fact, several studies using multilevel analyses have shown a correlation between different contextual area characteristics (e.g., social participation, income inequality, area socioeconomic deprivation, etc.) and individual health (Chaix, 2009; Pickett \& Pearl, 2001). However, an important issue is that the causal validity of most previous contextual analyses is today being seriously questioned (Merlo \& Chaix, 2006; Oakes, 2004, 2006).

An important concern when investigating area effects on individual health is that socio-economic segregation and self-selection create selective migration of individuals with particular characteristics to specific geographical contexts. This situation, in turn, leads to systematic errors in the estimation of causal contextual effects, and this bias is difficult to overcome by the usual statistical analysis applied to observational data. While the ideal design for studying causality is the randomized trial, this methodology presents major limitations, especially when the units of analysis are areas rather than individuals (Merlo \& Chaix, 2006). It is therefore highly relevant to both develop appropriate observational methods for causal analysis, and to review the evidence that has been gathered so far.

\section{Identifying relevant contexts, and considering vari- ance as a source of substantive information}

There are additional severe limitations in contextual epidemiology. First of all, the very definition of "context" is often based on administrative boundaries (e.g., census areas) rather than on the true spatial or cultural environments where individuals interact (Cummins, Curtis, Diez-Roux, \& Macintyre, 2007; Knox \& Pinch, 2006; Merlo, et al., 2009a). There is also a lack of knowledge on the mechanisms underlying cross-level (i.e., context-individual) associations.

Moreover, while normally social epidemiology is concerned with the identification of specific risk fac- 
tors for diseases by measuring changes in group means (e.g., increased area level socioeconomic deprivation could be associated with -or potentially cause- a higher individual risk for child maltreatment) many variables of interest may be associated with a change in the variance of the distribution of the dependent variable independently of its mean (Braumoeller, 2008; Downs \& Roche, 1979) (see for example Merlo, Asplund, Lynch, Rastam, \& Dobson, 2004; Ohlsson \& Merlo, 2007). In spite of this reasoning, variance is habitually considered a measure of uncertainty or a nuisance rather than a source of substantive information. This means-centric reductionism has dominated many of the multilevel analyses performed today, which is a kind of contradiction since understanding the distribution of variance across levels is a fundamental task in multilevel analyses. Using the words of Clarke: "without knowledge of the random components (i.e., variance), the interpretation of arealevel fixed effects parameters (i.e., measures of association) becomes decontextualized" (Clarke \& Wheaton, 2007, p.315).

The current means-centric reductionism existing in (social) epidemiology is mostly concerned with the identification of risk factors (Susser \& Susser, 1996a, $1996 b)$ and creates a paradoxical situation, as social medicine is not only interested in increasing the (mean) health of the population, but also in understanding and decreasing inappropriate health inequalities (variance) (Merlo, et al., 2009a).

Finally we need to integrate all the new information for planning and evaluating public health interventions.

\section{Approaching the research problems step by step}

Future research needs to answer the knowledge gaps and methodological challenges exposed above. For these purposes I propose a conceptual framework that can help us to investigate the role that contextual factors across the life-course play for understanding individual risk (independent of whether the risk concerns myocardial infarction or being a victim of IPV). This knowledge is necessary for planning and evaluating public health interventions. The framework identifies five main areas of research.

a) Identifying the relevant contexts and measuring general contextual effects.

b) Measuring contextual characteristics, specific contextual effects and underlying cross-level mechanisms.

c) Investigating general and specific contextual effects from a longitudinal, life-course perspective and across generations.

d) Developing quasi-experimental analysis (e.g., family-based designs) for the study of causal effects in observational contextual analyses. e) Using scientific knowledge for planning and evaluating interventions.

\section{(A) Identifying the relevant contexts}

\section{Identifying contexts by strength of the association contextual variables and individual health}

A fundamental question in contextual epidemiology is to identify the scale that best corresponds to meaningful contextual boundaries (e.g., neighbourhood) that influence individual health or health related behaviour (e.g., propensity for IPV). Identifying the right socio-geographical scale is relevant since it can be used for measuring pertinent contextual exposures (Chaix, Merlo, Evans, Leal, \& Havard, 2009; Chaix, Merlo, Subramanian, Lynch, \& Chauvin, 2005; Messer, 2007), and for recognizing the appropriate level for public health interventions. For this purpose, previous research has observed the strength of the associations between contextual variables (measured at different geographical scales) and individual health in order to identify the relevant context by the strength of the association (Diez Roux \& Mair; Mujahid, Diez Roux, Morenoff, \& Raghunathan, 2007). However, this approach may not always be appropriate because of the existence of the Modifiable Area Unit Problem (MAUP) (Holt, Steel, \& Tranmer, 1996). Openshaw (Openshaw, 1984) observed that "the areal units (zonal objects) used in many geographical studies are arbitrary, modifiable, and subject to the whims and fancies of whoever is doing, or did, the aggregating". Because of the MAUP, the association between variables depends on the size of areal units (i.e., the scale) for which data are reported. Generally, correlation increases as a real unit size increases. Moreover the "scale effect", the "zone effect" indicates variation in correlation statistics caused by the regrouping of data into different configurations at the same scale.

\section{Identifying the relevant contexts by measures of variance and clustering}

An alternative methodology for identifying the relevant contexts that influence individual health/behaviour is based on measures of variance and clustering, the rationale behind this approach has been extensively explained elsewhere (Larsen \& Merlo, 2005; Merlo, 2003; Merlo et al., 2006; Merlo, Chaix, Yang, Lynch, \& Rastam, 2005a, 2005b; Merlo, et al., 2009a; Merlo, Yang, Chaix, Lynch, \& Rastam, 2005). In short, the idea is that, in the same way as individual measurements of health indicators (e.g., blood pressure, smoking habits) are highly correlated within individuals, the health of the individuals within a 
Figure 1. Represents graphically the proposed conceptual framework. The framework stresses the importance of (A) identifying the boundaries delimiting the relevant context influencing individual health, (B) their specific characteristics, as well as the associations and underlying mechanisms linking those contextual characteristics with individual outcomes (C) across the life course. This framework emphasizes the relevance of considering "causality" (D) as a key aspect that needs be explicitly considered in all observational Epidemiology and especially when the units of analysis are both individual and contexts (e.g., neighbourhoods). Finally, (E) the accumulated scientific knowledge can be used for planning and evaluating interventions

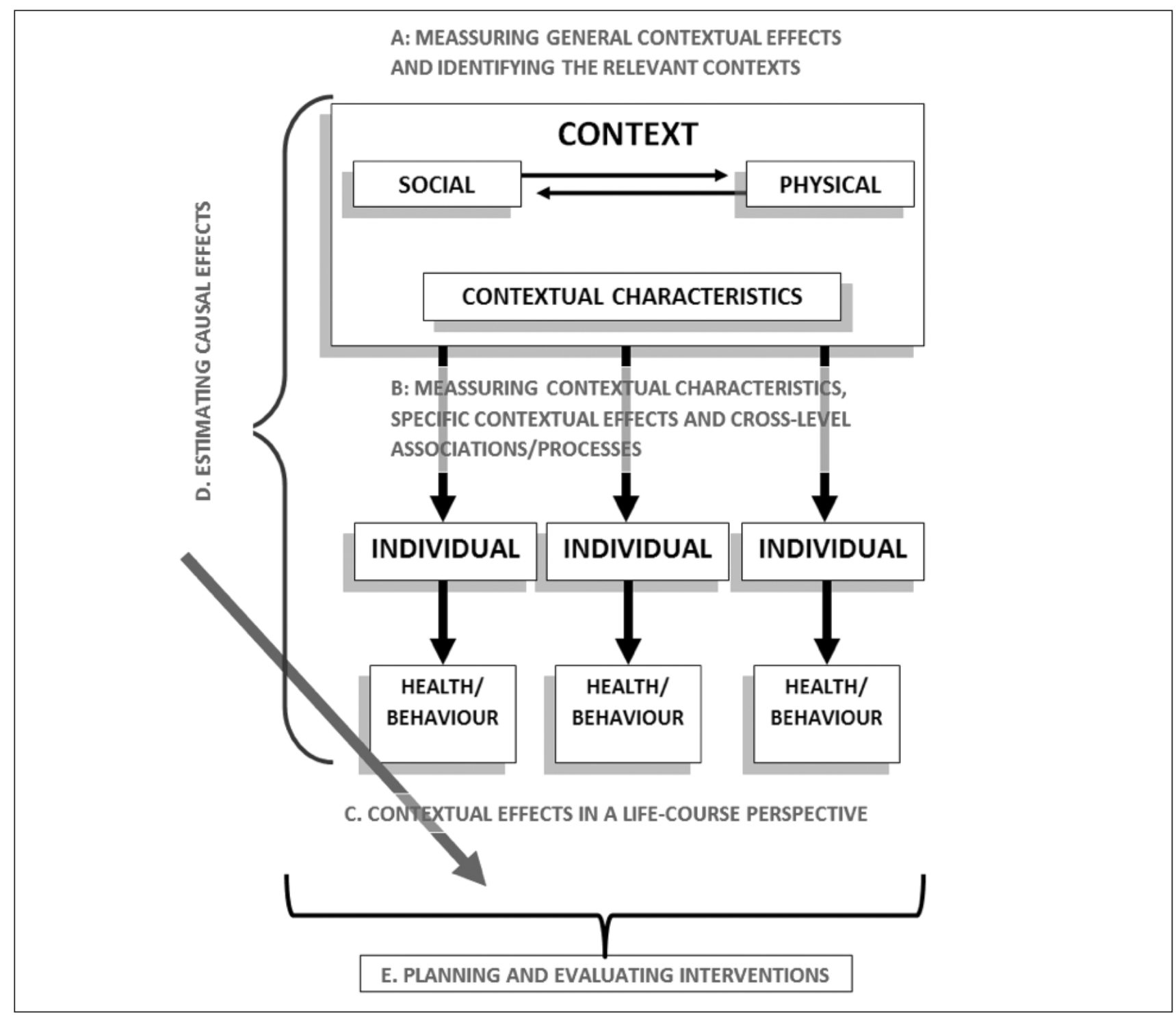

meaningful context is expected to be correlated. However, while the limits that define the individual bodies are very apparent, and we normally find very high intra-individual correlation of individual level measurements, the collective body's geographical or cultural limits that define the context (e.g., "neighbourhoods") are more difficult to discern and, often, this situation expresses itself by very low intra-context correlation of individual level outcomes. Nevertheless, the majority of contextual/multilevel analyses performed until now have relied on existing administrative boundaries without paying attention to the relevance of these contextual limits for understanding individual health variation (Merlo, et al., 2009a).

\section{Distinguishing between general and specific contex-} tual effects

It becomes clear that future research should focus on revisiting the validity of the administrative boundaries commonly used to conduct social epidemiological studies. Simultaneously we need to identify the contexts that are really relevant for specific individual outcomes. For this purpose, the analytical approach of components of health variation and the use of measures of variance and clustering (e.g., intra-class correlation coefficient, median odds ratio) (Larsen \& Merlo, 2005; Merlo, Chaix et al., 2005a) is very suitable as it allows the identification of general contextual effects. The idea is that before investigating specific contextu- 
al effects (e.g. the specific association between area deprivation and individual propensity for being a victim of IPV), it is relevant to estimate the size of the general contextual effects; that is, how much individual risk is conditioned by the context of the area as a whole (Merlo et al., 2009a).

When measuring general contextual effects we do not focus on any contextual characteristics other than the very boundaries that delimit the context under analysis. Considering this approach we can not only assess the scale on which contextual influences operate using geographical/administrative area boundaries (e.g., local neighbourhoods, parishes, city areas, municipalities, counties, countries) but also asses other life contexts like schools, work places, health care areas, hospitals. We can even investigate non-geographical boundaries based on geocultural (e.g., country of birth within a city; Beckman et al., 2004) or familial (e.g., households; Yang, Eldridge, \& Merlo, 2009) or family trees (Merlo, Bengtsson-Bostrom, Lindblad, Rastam, \& Melander, 2006) criteria. Applying multilevel analyses we can also investigate general contextual effects using a combination of different levels without a typical hierarchical structure (Browne, Goldstein, \& Rasbash, 2001). The identification of relevant contexts can be complemented by using Geographical Information System (GIS) and innovative techniques of cluster detection (Chaix et al., 2006; Chaix, Merlo, Subramanian, et al., 2005; Lynch et al., 2010).

By applying knowledge on social geography (Knox \& Pinch, 2006) and adopting a relational approach (Cummins et al., 2007) it could be possible to develop appropriate conceptualizations of places and contexts that affect specific individual outcomes (Macintyre, et al., 2002). General contextual effects are also relevant for planning strategies of prevention -especially when it comes to deciding whether public health resources should be directed to individuals or to communities in specific places and times (Merlo, 2003; Merlo, Ohlsson, Lynch, Chaix, \& Subramanian, 2009b).

\section{The family level}

One of the most relevant - but still rather neglectedlevels is the family. Family-based studies are fundamental multi-level analyses, since individuals are naturally nested within pedigrees and share numerous genetic and environmental factors that condition a common level of health over and above individual characteristics (Lawlor \& Mishra, 2009). In spite of this obvious dependence, the scarce attention that (social) epidemiologists have paid to the biological and social pedigrees, to which each individual belongs to, is rather surprising. It is very possible that many observed individual differences in risk factors for dis- ease can be explained by the general genetic/shared environmental backgrounds of the families. The family level is important for the planning of prevention strategies in the area of public health.

\section{Variance-altering causation, means centric reductionism, and multilevel analyses}

Another innovative perspective that needs be developed is the investigation of causes of changes in the variance (the so called variance-altering causation). This approach is of considerable interest for the evaluation of interventions applied at the contextual level, and for the analysis of health disparities across time. The concepts were previously commented on by Downs and Rocke (1979) and later by Gould (1996) and Braumoeller $(2006,2008)$ in research fields outside epidemiology and also applied independently by the author of this essay and his research group in recent studies (Merlo, et al., 2004; Ohlsson \& Merlo, 2007). These ideas are also applicable in modern multilevel regression analyses (Rasbash et al., 2000). While normally social epidemiology is concerned with the identification of specific risk factors for diseases by measuring changes in group means (e.g., a low level of social cohesion at the area level might cause a higher individual risk for being a victim of IPV) many variables of interest in epidemiology may cause a change in the variance of the distribution of the outcome variable independently of their effects on the mean. For example, in a recent study (Ohlsson \& Merlo, 2007), variance altering factors were explicitly investigated and a conceptual illustration presented showed that a change in the characteristics of a context (i.e., the implementation of a decentralised health care budget) not only changed the mean of the distribution of the variable studied (i.e., increasing compliance with guidelines for prescription of pharmacological agents), but also altered the variance between the collective units as well (i.e., decreasing disparities between health care centres). Downs and Rocke (1979) and Braumoeller (2006, 2008) also provide illustrative examples in their work.

Today, there is a clear means-centric reductionism in epidemiology that is mostly concerned with finding risk factors. Paradoxically, this reductionism has been the norm in many multilevel investigations, whereas understanding the distribution of variance across levels should be the sine qua non of any solid multilevel analysis (Clarke \& Wheaton, 2007; Merlo, Chaix, et al., 2005a; Riva, Gauvin, \& Barnett, 2007). Future research should question this usual means-centric approach and emphasise the need to deliberately investigate the heterogeneity that underlies averages. It is necessary to investigate both changes in group means and changes in variance and develop new epidemiological measures using this approach. 
Occasionally the explicit focus of research in conventional epidemiology is the investigation of geographical variance. This is the case in the classical "ecological analyses"(Engstrom et al., 2000) as well as in the so called "small area variation studies" (Folland \& Stano, 1989) and "spatial analyses" (Jerrett et al., 2003). However, such epidemiological analyses are performed at the aggregated ecological scale disregarding individual level information. It is necessary to question these analytical approaches and emphasize the relevance of including both individual and contextual level information across time.

\section{(B) Measuring contextual characteristics, their specific contextual effects and their underlying cross-level mechanisms}

After assessing the extent to which individual outcomes (e.g., health related behaviour, risk factors, disease risk, health care utilisation, IPV or child maltreatment) are conditioned by a context (see section 'A' above), the next challenge is conceptualizing and measuring the specific contextual properties of the social and physical environment that are hypothesized to be relevant for these individual outcomes (Cummins, et al., 2007; Macintyre, et al., 2002). We can apply the theories that are actual in social epidemiology (Krieger, 2001) or social psychology and operationalize contextual variables (Johnell, 2006). We can use different techniques available for contextual measurement.

Besides direct information on the physical environment (e.g., noise, air pollution, green environment), it is possible to apply spatial and GIS analysis (Chaix et al., 2005) to measure the properties of the material environment by geocoding data on community resources (e.g., sport equipment, health care facilities). Also, by means of "ecometric" methodology (Sampson, Raudenbush, \& Earls, 1997) it is possible to obtain reliable measures of social contexts (e.g., social cohesion) using information from samples of the population in available questionnaire surveys (Chaix, Rosvall, \& Merlo, 2007).

When it comes to the identification of mechanisms explaining associations between contextual characteristics and individual outcomes, we need to consider and contrasts two possibly complementary hypotheses in social medicine: the psychosocial and the neo-materialist (Adamson, Ebrahim, \& Hunt, 2006; Lynch, Smith, Kaplan, \& House, 2000; Marmot \& Wilkinson, 2001; Muntaner, Lynch, \& Smith, 2001; Wilkinson, 1997). In this dialectic, the possible existence of psychosocial mechanisms behind a possible association needs be systematically revised on the light of a materialistic perspective that considers the lack of access to material resources as a major determinant of individual health and health related behaviour. At this point it is worthy to reflect on the ideas expressed by Muntaner (2005) "We understand ideology as a system of factual statements and value judgments that inspires social, including public health, policies. Given such definition, psychosocial epidemiology becomes mostly ideological when the policies it inspires lack scientific justification (for example, "subjective stress is the major social determinant of cardiovascular mortality, therefore we should focus on changing people's perceptions of their social and work environment")... Thus, to provide more accurate and useful accounts of how society affects health, (we need) models in which social structure and psychosocial exposures are integrated into mechanisms that influence population patterns of mortality and morbidity".

Finally, a major caveat in contextual analyses is to separate the effect of specific contextual characteristics (Geronimus \& Bound, 1998). For example, neighbourhood levels of social capital, percentage of people with high education or percentage of emigrants are highly correlated variables. This phenomenon motivates the creation of composite indexes of deprivation (Carstairs, 1995; Folwell, 1995; Gordon, 1995). That is, on the one hand, choosing one variable instead of other variable may produce a false impression of theoretical specificity and, on the other hand, the interpretation of composite indexes is very diffuse (Geronimus \& Bound, 1998). As expressed by an author "The alternatives... for choosing contextual variables... could be characterized as dishonest specificity and honest ambiguity" (Bingenheimer \& Raudenbush, 2004).

\section{(C) Investigating general and specific contextual effects from a longitudinal, life-course per- spective, and across generations}

Looking back to the recent history of social epidemiology we could distinguish three intellectual generations (Merlo, 2010). The first generation was concerned with a simple degenerative aetiological model, focused on adult risk factors for chronic complex diseases. This initial generation appears to be obsolete, when the second intellectual generation adopts a development approach that integrates the degenerative model in a life-course approach and studies the effects on health and health-related outcomes of biological (including genetics), environmental and social exposures during gestation, infancy, childhood, adolescence, adulthood and across generations (Kuh, BenShlomo, Lynch, Hallqvist, \& Power, 2003). However, while many life-course studies still employ epidemiological methods similar to those used in the degenerative aetiological model, the third generation of epidemiologists incorporates unusual study designs (e.g. inter-generational, siblings, twins, etc.) as their fundamental analytical tools (Lawlor, et al., 2009). 
The conceptual framework that we describe here aims to systematically understand how socially-patterned exposures at different stages of life and across different contexts, influence health later in life (Kuh et al., 2003). It is known that individual exposure to both early and later life socioeconomic disadvantage affects disease risk (Davey Smith et al., 2002). There are established hypotheses on how exposure across the life-course effects individual health (i.e., the critical period, the social mobility, and the cumulative models; Rosvall, Chaix, Lynch, Lindstrom, \& Merlo, 2006). However, it is not well understood how cumulative exposure to different social environments influences individual disease risk over and above current individual characteristics (e.g., socio-economic position).

In a life-course developmental framework, the effects of various aspects of the environment are literally "embodied" over time so that in some cases, what is assigned as an individual-level variable at one time point could equally be conceptualized as a characteristic of past environments in which the individuals grew up. For example, developmental contexts can influence smoking but when cross-sectional analyses of contextual effects are examined, smoking is often controlled for as an "individual characteristic".

Contextual influences on childhood and adult health need to be investigated in periods earlier in the life course (e.g., childhood, intrauterine period) (Bengtsson \& Lindstrom, 2003), rather than in crosssectional analysis in adults. In addition, we also need to consider that selective residential mobility -i.e., unhealthy individuals moving to deprived neighbourhoods - is part of the process that drives compositional area differences, and that the environments themselves change over time. Furthermore, each individual is simultaneously exposed to several contexts, and these contexts change across the life course (Naess, Claussen, Smith, \& Leyland, 2008; Ohlsson \& Merlo, 2010). In this framework, and in connection with concepts explained before (section A) the ideas on time geography developed by Torsten Hägerstrand (1981) are of special relevance.

That is, we need to investigate how changes in both individual and contextual socioeconomic factors across the life course are associated with individual health. In addition, applying the idea "measures of variance" explained above (section A), we need not only identify the relevant contexts but also disentangle the relative relevance of different contexts (e.g., neighbourhoods) across the life course (Naess, et al., 2008; Ohlsson \& Merlo, 2010).

\section{(D) Developing quasi-experimental family-based designs for the analysis of causal effects in observational multilevel analyses}

The proposed framework stresses the importance of adopting quasi-experimental, family-based designs
(Goodnight et al., 2011 ; Lahey \& D'Onofrio, in press; Lawlor et al., 2009; Merlo, 2010) for analysing and understanding life-course determinants of health across generations (Lawlor, et al., 2009; Merlo, 2010; Merlo, Bengtsson-Bostrom et al., 2006). Family-based designs also allow us to disentangle genetic effects from shared family effects and non-shared individuallevel effects and thereby to understand genetic and socio-environmental determinants of health. Moreover, the family-based approach is very appropriate for improving analyses of causality in observational epidemiology (Merlo, 2010).

A classical limitation in observational epidemiology is the difficulty in finding counter-factual circumstances for drawing appropriate conclusions on average causal effects (Harding, 2003; Hernan \& Robins, 2006), and this problem is especially relevant when investigating contextual effects on health (Harding, 2003; Oakes, 2004; Subramanian, 2004). Classical observational approaches try to reduce the effect of confounding by adjusting for numerous variables in multiple regression analyses, or by applying techniques like propensity scoring and inverse probability weighting (Hernan \& Robins, 2006). However, the threat of residual confounding is difficult to eliminate. While randomized trials are the ideal study design for investigating causality, they are also subject to many limitations especially when the units of analysis are whole communities rather than individuals (Merlo \& Chaix, 2006). The methodological challenges inherent to the estimation of causal contextual effects (e.g., identification of the relevant boundaries, Merlo et al., 2009b; endogeneity, Oakes, 2004; the so called "structural confounding", Messer, Oakes, \& Mason, 2010; and excessive extrapolation in multilevel regression analyses, Oakes, 2004) has led some authors to conclude that knowledge on contextual effects could better be achieved by qualitative approaches (Cummins et al., 2007).

Family-based quasi-experimental studies take advantage of the intra-familial correlation of the information and allow improved counterfactual designs for investigating causal effects in observational multilevel analyses (Merlo, 2010). The comparison of genetically related individuals that differ regarding their exposure to contextual factors (e.g., siblings living in different residential areas as adults) is a powerful strategy for studying causal relationships between contextual area characteristics and individual outcomes. Quasi-experimental family based designs provides opportunities for investigating, ceteris paribus, the effects of different contextual exposure in genetically related individuals (e.g., twins, full siblings) that also share a similar family environment. This approach allows us to greatly reduce confounding compared to classical approaches. As far we know, this methodology has been rarely applied in contextual/neighbourhood research (Goodnight et al., 2011; Harding, 2003). 


\section{(E) Using scientific knowledge for planning and evaluating interventions}

The research strategies I have proposed above may produce worthy information for the planning and evaluation of public health interventions. The measurement of general contextual effects is highly appropriate for identifying the relevant contextual boundaries that affects individual health and health related behaviour and, thereby, for planning strategies of prevention focused on the right level of intervention. This information is especially relevant when it comes to deciding whether public health resources should be directed to individuals or to communities in specific places and times (Merlo, 2003; Merlo et al., 2009b).

It is also relevant to identify the relative importance of the different context individual are exposed in a concrete time and across the life course. The combined analysis of measures of association (i.e., the mean-centric approach) and measures of variation (i.e., measures of clustering and the approach of variance-altering causation) is suitable for evaluating the effects of contextual interventions on individual outcomes (see for example Hjerpe, Ohlsson, Lindblad, Bostrom, \& Merlo, 2011; Ohlsson \& Merlo, 2007). Overall, we need to pay special attention to the causal validity of the contextual factors we think affect individual health and health related behaviour.

Social epidemiology, social psychology and psychosocial intervention share many knowledge and research interests and will likely benefit by an increased cross-pollination.

\section{Acknowledgments}

The study was funded by the Swedish Council for working life and social research (FAS) (Dnr: 20100402) and the Swedish Research Council (VR) (Dnr K2011-69X-15377-07-6).

\section{References}

Adamson, J. A., Ebrahim, S., \& Hunt, K. (2006). The psychosocial versus material hypothesis to explain observed inequality in disability among older adults: Data from the West of Scotland Twenty-07 Study. Journal of Epidemiology and Community Health, 60, 974-980.

Beckman, A., Merlo, J., Lynch, J. W., Gerdtham, U. G., Lindstrom, M., \& Lithman, T. (2004). Country of birth, socioeconomic position, and healthcare expenditure: A multilevel analysis of Malmö, Sweden. Journal of Epidemiology and Community Health, 58, 145-149.

Ben-Shlomo, Y., \& Kuh, D. (2002). A life course approach to chronic disease epidemiology: Conceptual models, empirical challenges and interdisciplinary perspectives. International Journal of Epidemiology, 31, 285-293.

Bengtsson, T., \& Lindstrom, M. (2003). Airborne infectious diseases during infancy and mortality in later life in southern Sweden, 1766-1894. International Journal of Epidemiology, 32, 286-294.
Bingenheimer, J. B., \& Raudenbush, S. W. (2004). Statistical and substantive inferences in public health: issues in the application of multilevel models. Annual Review of Public Health, 25, 53-77.

Braumoeller, B. (2006). Explaining variance; Or, stuck in a moment we can't get out of. Political Analysis, 14, 268-290.

Braumoeller, B. F. (2008). Explaining variance-rethinking social causation. Draft, v. 1.5.1. http://wwweconomiaunimiit/users/iacus/gs/aa0304/variancepdf (by 22 November 2008).

Browne, W. J., Goldstein, H., \& Rasbash, J. (2001). Multiple membership multiple classification (MMMC) models. Statistical Modelling, 1, 103-124.

Carstairs, V. (1995). Deprivation indices: Their interpretation and use in relation to health. Journal of Epidemiology and Community Health, 49, 3-8.

Chaix, B. (2009). Geographic life environments and coronary heart disease: A literature review, theoretical contributions, methodological updates, and a research agenda. Annual Review of Public Health, 30, 81-105.

Chaix, B., Leyland, A. H., Sabel, C. E., Chauvin, P., Rastam, L., Kristersson, H., et al. (2006). Spatial clustering of mental disorders and associated characteristics of the neighbourhood context in Malmo, Sweden, in 2001. Journal of Epidemiology and Community Health, 60, 427-435.

Chaix, B., Merlo, J., Evans, D., Leal, C., \& Havard, S. (2009). Neighbourhoods in eco-epidemiologic research: Delimiting personal exposure areas. A response to Riva, Gauvin, Apparicio and Brodeur. Social Science \& Medicine, 69, 1306-1310.

Chaix, B., Merlo, J., Gaignard, J., Lithman, T., Boalt, A., \& Chauvin, P. (2005). The social and spatial distribution of mental and behavioral disorders related to psychoactive substance use in the city of Malmö, Sweden, 2001. In F. Colombus (ed.), Focus on lifestyle and health research. New York, USA: Nova Science Publishers.

Chaix, B., Rosvall, M., \& Merlo, J. (2007). Assessment of the magnitude of geographical variations and socioeconomic contextual effects on ischaemic heart disease mortality: A multilevel survival analysis of a large Swedish cohort. Journal of Epidemiology and Community Health, 61, 349-355.

Chaix, B., Merlo, J., Subramanian, S. V, Lynch, J., \& Chauvin, P. (2005). Comparison of a spatial perspective with the multilevel analytical approach in neighborhood studies: The case of mental and behavioral disorders due to psychoactive substance use in Malmo, Sweden, 2001. American Journal of Epidemiology, 162, 171-182.

Clarke, P., \& Wheaton, B. (2007). Addressing data sparseness in contextual population research: Using cluster analysis to create synthetic neighborhoods. Sociological Methods Research, 35, 311-351.

Cummins, S., Curtis, S., Diez-Roux, A. V., \& Macintyre, S. (2007). Understanding and representing 'place' in health research: A relational approach. Social Science \& Medicine, 65, 1825-1838.

Davey Smith, G., Ben-Shlomo, Y., \& Lynch, J. W. (2002). Lifecourse approaches to inequalities in coronary heart disease risk. In S. A. Stansfeld, \& M. G. Marmot (eds.), Stress and the heart psychosocial pathways to coronary heart disease. London: BMJ Books.

Davey Smith, G., \& Lynch, J. W. (2003). Socioeconomic differentials. In D. Kuh, \& Y. A. Ben-Shlomo (eds.), 
Lifecourse approach to chronic disease epidemiology. Oxford: Oxford University Press.

Diez Roux, A. V., \& Mair, C. (2010). Neighborhoods and health. Annals of the New York Academy of Sciences, 1186, 125-145.

Downs, G. W., \& Roche, D. M. (1979). Interpreting heteroscedasticity. American Journal of Political Science, $23,816-828$.

Engstrom, G., Berglund, G., Goransson, M., Hansen, O., Hedblad, B., Merlo, J., et al. (2000). Distribution and determinants of ischaemic heart disease in an urban population. A study from the myocardial infarction register in Malmo, Sweden. Journal of Internal Medicine, 247, 588-596.

Folland, S., \& Stano, M. (1989). Sources of small area variations in the use of medical care. Journal of Health Economics, 8, 85-107.

Folwell, K. (1995). Single measures of deprivation. Journal of Epidemiology and Community Health, 49, 51-56.

Geronimus, A. T., \& Bound, J. (1998). Use of census-based aggregate variables to proxy for socioeconomic group: Evidence from national samples. American Journal of Epidemiology, 148, 475-486.

Goodnight, J. A., Lahey, B. B., Van Hulle, C. A., Rodgers, J. L., Rathouz, P.J., Waldman, I. D., et al. (2011). A quasiexperimental analysis of the influence of neighborhood disadvantage on child and adolescent antisocial behavior. (Under revision).

Gordon, D. (1995). Census based deprivation indices: Their weighting and validation. Journal of Epidemiology and Community Health, 49, 39-44.

Gould, S. J. (1996). Full house: The spread of excellence from Plato to Darwin. New York: Three Rivers Press.

Harding, D. J. (2003). Counterfactual models of neighborhood effects: The effect of neighborhood poverty on dropping out and teenage pregnancy. American Journal of Sociology, 109, 676-719.

Hernan, M. A., \& Robins, J. M. (2006). Estimating causal effects from epidemiological data. Journal of Epidemiology and Community Health, 60, 578-586.

Hjerpe, P., Ohlsson, H., Lindblad, U., Bostrom, K. B., \& Merlo, J. (2011). Understanding adherence to therapeutic guidelines: A multilevel analysis of statin prescription in the Skaraborg Primary Care Database. European Journal of Clinical Pharmacology, 67, 415-423.

Holt, D., Steel, D. G., \& Tranmer, M. (1996). Area homogeneity and the modifiable areal unit problem. Geographical Systems, 3, 181-200.

Hägerstrand, T., \& Pred, A. (1981). Space and time in geography: Essays dedicated to Torsten Hägerstrand. Lund: CWK Gleerup.

Jerrett, M., Burnett, R. T., Goldberg, M. S., Sears, M., Krewski, D., Catalan, R., et al. (2003). Spatial analysis for environmental health research: concepts, methods, and examples. Journal of Toxicology and Environmental Health, Part A, 66, 1783-1810.

Johnell, K., Mansson, N. O., Sundquist, J., Melander, A., Blennow, G., \& Merlo, J. (2006). Neighborhood social participation, use of anxiolytic-hypnotic drugs, and women's propensity for disability pension: a multilevel analysis. Scandinavian Journal of Public Health, 34, 41-48.

Kaplan, G. A. (1999). What is the role of the social environment in understanding inequalities in health? Annals of the New York Academy of Sciences, 896, 116-119.

Knox, P. L., \& Pinch, S. (2006). Urban social geography: An introduction. Essex, England: Pearson Education Limited.

Krieger, N. (2001). Theories for social epidemiology in the 21st century: An ecosocial perspective. International Journal of Epidemiology, 30, 668-677.

Kuh, D., Ben-Shlomo, Y., Lynch, J., \& Hallqvist, J. (2003). Power C. Life course epidemiology. Journal of Epidemiology and Community Health, 57, 778-783.

Lahey, B. B., \& D'Onofrio, B. M. (in press). All in the family: Comparing siblings to test causal hypotheses regarding environmental influences on behavior. Current Directions in Psychological Science.

Larsen, K., \& Merlo, J. (2005). Appropriate assessment of neighborhood effects on individual health: Integrating random and fixed effects in multilevel logistic regression. American Journal of Epidemiology, 161, 81-88.

Lawlor, D. A., \& Mishra, G. D., (2009). Family matters. Designing, analysing and understanding family-based studies in life-course epidemiology. New York: Oxford University Press.

Lynch, J. W., \& Kaplan, G. A. (2000). Socioeconomic position. In L. F. Berkman, \& I. Kawachi (eds.), Social epidemiology. New York: Oxford University Press (pp. 13-35).

Lynch, J. W., Smith, G. D., Kaplan, G. A., \& House, J. S. (2000). Income inequality and mortality: Importance to health of individual income, psychosocial environment, or material conditions. British Medical Journal, 320, 1200-1204.

Lynch, K. F., Subramanian, S. V., Ohlsson, H., Chaix, B., Lernmark, A. A., \& Merlo, J. (2010). Context and disease when disease risk is low: The case of type 1 diabetes in Sweden. Journal of Epidemiology and Community Health, 64, 789-795.

Macintyre, S., Ellaway, A., \& Cummins, S. (2002). Place effects on health: How can we conceptualise, operationalise and measure them? Social Science \& Medicine, 55, 125-139.

Marmot, M., \& Wilkinson, R. G. (2001). Psychosocial and material pathways in the relation between income and health: a response to Lynch et al. British Medical Journal, $322,1233-1236$.

Merlo, J. (2003). Multilevel analytical approaches in social epidemiology: Measures of health variation compared with traditional measures of association. Journal of Epidemiology and Community Health, 57, 550-552.

Merlo, J. (2010). Book review. Family matters: Designing, analysing and understanding family-based studies in lifecourse epidemiology. Debbie A Lawlor, Gita D Mishra (eds.). International Journal of Epidemiology, 39, 936937.

Merlo, J., Asplund, K., Lynch, J., Rastam, L., \& Dobson, A. (2004). Population effects on individual systolic blood pressure: A multilevel analysis of the World Health Organization MONICA Project. American Journal of Epidemiology, 159, 1168-1179.

Merlo, J., Bengtsson-Bostrom, K., Lindblad, U., Rastam, L., \& Melander, O. (2006). Multilevel analysis of systolic blood pressure and ACE gene I/D polymorphism in 438 Swedish families - a public health perspective. BMC Medical Genetics, 7, 14. 
Merlo, J., \& Chaix, B. (2006). Neighbourhood effects and the real world beyond randomized community trials: A reply to Michael J. Oakes. International Journal of Epidemiology, 35, 1361-1363.

Merlo, J., Chaix, B., Ohlsson, H., Beckman, A., Johnell, K., Hjerpe, P., et al. (2006). A brief conceptual tutorial of multilevel analysis in social epidemiology: Using measures of clustering in multilevel logistic regression to investigate contextual phenomena. Journal of Epidemiology and Community Health, 60, 290-297.

Merlo, J., Chaix, B., Yang, M., Lynch, J., \& Rastam, L. (2005a). A brief conceptual tutorial of multilevel analysis in social epidemiology: Linking the statistical concept of clustering to the idea of contextual phenomenon. Journal of Epidemiology and Community Health, 59, 443-449.

Merlo, J., Chaix, B., Yang, M., Lynch, J., \& Rastam, L. (2005b). A brief conceptual tutorial on multilevel analysis in social epidemiology: Interpreting neighbourhood differences and the effect of neighbourhood characteristics on individual health. Journal of Epidemiology and Community Health, 59, 1022-1028.

Merlo, J., Ohlsson, H., Lynch, K. F., Chaix, B., \& Subramanian, S. V. (2009a). Individual and collective bodies: Using measures of variance and association in contextual epidemiology. Journal of Epidemiology \& Community Health, 63, 1043-1048.

Merlo, J., Ohlsson, H., Lynch, K. F., Chaix, B., \& Subramanian, S. V. (2009b). Individual and collective bodies: Using measures of variance and association in contextual epidemiology. Journal of Epidemiology and Community Health, 63, 1043-1048.

Merlo, J., Yang, M., Chaix, B., Lynch, J., \& Rastam, L. (2005). A brief conceptual tutorial on multilevel analysis in social epidemiology: Investigating contextual phenomena in different groups of people. Journal of Epidemiology and Community Health, 59, 729-736.

Messer, L. C. (2007). Invited commentary: Beyond the metrics for measuring neighborhood effects. American Journal of Epidemiology, 165, 868-871.

Messer, L. C., Oakes, J. M., \& Mason, S. (2010). Effects of socioeconomic and racial residential segregation on preterm birth: A cautionary tale of structural confounding. American Journal of Sociology, 171, 664-673.

Mujahid, M. S., Diez Roux, A. V., Morenoff, J. D., \& Raghunathan, T. (2007). Assessing the measurement properties of neighborhood scales: From psychometrics to ecometrics. American Journal of Epidemiology, 165, 858-867.

Muntaner, C., \& Chung, H. J. (2005). Psychosocial epidemiology, social structure, and ideology. Journal of Epidemiology and Community Health, 59, 540-541.

Muntaner, C., Lynch, J., \& Smith, G. D. (2001). Social capital, disorganized communities, and the third way: Understanding the retreat from structural inequalities in epidemiology and public health. International Journal of Health Services, 31, 213-237.

Naess, O., Claussen, B., Smith, G. D., \& Leyland, A. H. (2008). Life course influence of residential area on causespecific mortality. Journal of Epidemiology and Community Health, 62, 29-34.
Oakes, J. M. (2004). The (mis)estimation of neighborhood effects: Causal inference for a practicable social epidemiology. Social Science \& Medicine, 58, 1929-1952.

Oakes, J. M. (2006). Commentary: Advancing neighbourhood-effects research-selection, inferential support, and structural confounding. International Journal of Epidemiology, 35, 643-647.

Ohlsson, H. \& Merlo, J. (in press). Place effects for areas defined by administrative boundaries: A life course analysis of mortality and cause specific morbidity in Scania, Sweden, 2010. Social Science \& Medicine.

Ohlsson, H., \& Merlo, J. (2007). Understanding the effects of a decentralized budget on physicians compliance with guidelines for statin prescription: A multilevel methodological approach. BMC Health Services Research, 7, 68.

Ohlsson, H., Rosvall, M., Hansen, O., Chaix, B., \& Merlo, J. (2010). Socioeconomic position and secondary preventive therapy after an AMI. Pharmacoepidemiolofy and Drug Safety, 19, 358-366.

Openshaw, S. (1984). The modifiable areal unit problem. Norwich: Geo Books.

Pickett, K. E., \& Pearl, M. (2001). Multilevel analyses of neighbourhood socioeconomic context and health outcomes: A critical review. Journal of Epidemiology \& Community Health, 55, 111-122.

Rasbash, J., Browne, W., Goldstein, H., Yang, M., Plewis, I., Healy, M., et al. (2000). Modelling the variance as a function of explanatory variables A user's guide to MLwiN. http://multilevel.ioe.ac.uk/download/userman.pdf (version 2.1 ed., pp. 77-88): Multilevels Models Project, Institute of Education, University of London.

Riva, M., Gauvin, L., \& Barnett, T. A. (2007). Toward the next generation of research into small area effects on health: A synthesis of multilevel investigations published since July 1998. Journal of Epidemiology and Community Health, 61, 853-861.

Rosvall, M., Chaix, B., Lynch, J., Lindstrom, M., \& Merlo J. (2006). Similar support for three different life course socioeconomic models on predicting premature cardiovascular mortality and all-cause mortality. BMC Public Health, 6, 203.

Sampson, R. J., Raudenbush, S. W., \& Earls, F. (1997). Neighborhoods and violent crime: a multilevel study of collective efficacy. Science, 277, 918-924.

Subramanian, S. V. (2004). The relevance of multilevel statistical methods for identifying causal neighborhood effects. Social Science \& Medicine, 58, 1961-1967.

Susser, M., \& Susser, E. (1996a). Choosing a future for epidemiology: I. Eras and paradigms. American Journal of Public Health, 86, 668-673.

Susser, M., \& Susser, E. (1996b). Choosing a future for epidemiology: II. From black box to Chinese boxes and eco-epidemiology. American Journal of Public Health, 86, 674-677.

Wilkinson, R. G. (1997). Socioeconomic determinants of health. Health inequalities: Relative or absolute material standards? British Medical Journal, 314, 591-595.

Yang, M., Eldridge, S., \& Merlo, J. (2009). Multilevel survival analysis of health inequalities in life expectancy. International Journal for Equity in Health, 8, 31.

Manuscript received: 16/12/2010

Review received: 18/02/2011

Accepted: 18/02/2011 